\title{
A relação entre o uso de drogas e o trabalho: uma revisão de literatura PSI
}

\section{The relationship between drug use and work: a literature PSI review}

\section{La relación entre el consumo de drogas y el trabajo: una revisión de la literatura PSI}

\author{
I tamar J osé Felix J unior* \\ Universidade Federal de Rondônia - UNIR, Porto Velho, Rondônia, Brasil \\ Vanderléia de Lurdes Dal Castel Schlindwein** \\ Universidade Federal de Rondônia - UNIR, Porto Velho, Rondônia, Brasil
}

Paulo Renato Vitória Calheiros***

Universidade Federal de Rondônia - UNIR, Porto Velho, Rondônia, Brasil

\begin{abstract}
RESUMO
As teorias relacionadas ao tema "Saúde mental e trabalho" têm dado a devida importância ao fato de que, cada vez mais, o adoecimento, o sofrimento mental e outros problemas sociais possuem vinculação com o trabalho, embora este último tenha passado por transformações tecnológicas e gerenciais com vistas a melhorar o bem-estar do trabalhador. Este artigo tem como objetivo fazer uma revisão de literatura PSI sobre estudos que abarcam o uso de substâncias psicoativas e sua relação com o trabalho. Para isso foram consultadas as bases de dados Pepsic, SciELO, Scopus e Web of Science. Como critério metodológico delimitou-se o período de 2005 a 2015. Foram encontrados 18 artigos, dos quais foram analisados 14 artigos que atendiam aos objetivos propostos. Observou-se que tem aumentado o uso de substâncias psicoativas por trabalhadores dentro do ambiente de trabalho. Os estudos sobre o tema evidenciam que, a relação entre trabalho e uso de substâncias psicoativas é encoberta pelo medo e pela estigmatização dentro das instituições, situação que dificulta e até impossibilita o acesso ao tratamento. Os autores sugerem que sejam feitos trabalhos de prevenção nas empresas ou instituições e que sejam realizados trabalhos de intervenção ou tratamento especializado para essa população.

Palavras-chave: trabalho, sofrimento, dependência química, estigma.
\end{abstract}

\section{ABSTRACT}

The theories associated to the topic of "Mental Health and Work" have given the necessary importance to the fact that diseases, psychic pain and other social problems have become more and more evident due to the setbacks of work, even though work has passed through technologic and managerial transformations to improve the workers' welfare. This article aimed to 
develop a literature review of studies that approach the use of psychoactive substances by workers. As such, Pepsic, Scielo, Scopus and Web of Science databases were consulted. 18 articles were found, out of which the 14 that complied with the proposed goals, were analysed. It was observed that the use of psychoactive substances by workers inside workplaces has increased. The studies about the topic demonstrate that the relation between work and the use of psychoactive substances is disguised by fear and stigmatization inside the institutions. This situation makes the access to treatment more difficult or even impossible. The authors suggest that prevention campaigns be held inside companies and institutions as well as interventions or specialized treatment for this population.

Keywords: work, suffering, chemical dependence, stigma.

\section{RESUMEN}

Las teorías relacionadas con el tema "La salud mental y el trabajo" han dado la debida importancia al hecho de que cada vez más la enfermedad, el sufrimiento mental y otros problemas sociales han surgido debido a los reveses de trabajo, aunque este último ha experimentado cambios tecnológicos y gestión con el fin de mejorar el bienestar de los trabajadores. Este artículo tiene como objetivo hacer una revisión bibliográfica de los estudios que incluyen el uso de sustancias psicoactivas por los trabajadores. Para que se consultó a las bases de datos SciELO Pepsic, Scopus y Web of Science. Como criterios metodológicos delimitados para el período 20052015 se han encontrado 18 artículos de los cuales se analizaron 14 artículos que cumplieron los objetivos. Se observó que se ha incrementado el uso de sustancias psicoactivas por los trabajadores en el lugar de trabajo. Estudios sobre el tema muestran que la relación entre el trabajo y el consumo de sustancias psicoactivas está envuelto por el miedo y el estigma dentro de las instituciones, lo que impede y incluso dificulta el acceso al tratamiento. Los autores sugieren que se hacen de la labor de prevención en las empresas o instituciones y se llevan a cabo estudios de intervención o tratamiento especializado para esta población.

Palabras-Clave: trabajo, sufrimiento, adicción a sustancias, estigma.

\section{I ntrodução}

O trabalho é considerado uma das formas de desenvolvimento pessoal e social do indivíduo, contribuindo para a formação de laços, para a expressão da subjetividade e para as vivências de prazer. $O$ produto gerado pelo trabalho é característico no papel do desenvolvimento de um país, estado ou cidade, e também de uma família, considerada um coadjuvante na qualidade de vida e saúde. Além do mais, o trabalho não se configura como a única essência que diferencia os humanos de outros animais, o homem tem também outras características, como a linguagem, o lazer, a religião e a guerra. Todos esses constructos têm como características 0 reconhecimento ao indivíduo que o faz (Enriquez, 2014).

Nos últimos anos diversas teorias têm estudado a relação do indivíduo com o trabalho, entre as quais se destaca a da "Psicodinâmica do Trabalho", de Dejours (2010, 2011, 2012). 
Enfatizando a relação entre sofrimento e prazer no trabalho, vários estudos desta teoria indicam que o trabalho também é um fator que contribui para o adoecimento, seja físico ou mental (Ludermir, 2005; Rosa \& Carlotto, 2005, Dejours, 2010; Jardim, 2011) Atualizou-se o ano da reimpressão do livro de Dejours e citou-se as referências em ordem decrescente, além de corrigir a palavra acima grifada "trabalho") O debate sobre sofrimento tem se acentuado nos últimos anos e passou a ser estudado em vários lugares do mundo e em diferentes setores do trabalho.

Por outro lado, a "Psicodinâmica do Trabalho" refere-se ao trabalhador como um sujeito que vivencia afetivamente a experiência do real. A abordagem retoma conceitos psicanalíticos, mas com um viés mais social e coletivo, para se inserir como teoria e prática e assim viabilizar estudos e intervenções que discutam a mobilização subjetiva diante do desafio em que se constitui a organização do trabalho. Nesse sentido, o trabalho desgasta as defesas psíquicas, deixando o indivíduo sem defesas contra o sofrimento. Em suma, os problemas relacionados ao trabalho têm se intensificado, e a otimização e resolução desses problemas envolvem questões como as avaliações de desempenho, reuniões extensivas, reuniões motivacionais, castigos, punições e a alta rotatividade de pessoas e diminuição de cargos de trabalho (Barreto \& Heloani, 2014). Essa exacerbação do sofrimento no trabalho leva à crescente prescrição de antidepressivos e ansiolíticos nas empresas (Brant \& Minayo-Gomes, 2004).

Os estudos iniciais, com a "Psicopatologia do Trabalho", desvendaram diversos fatores que contribuem para o sofrimento no trabalho. Esses estudos tinham como objetivo compreender as causas coletivas da situação e da organização do trabalho em meio a este fenômeno, procurando focalizar as especificidades do sujeito e de seu trabalho, dando, assim, ênfase às análises das estratégias defensivas individuais e coletivas adotadas pelos trabalhadores para preservar 0 equilíbrio psíquico (Lima, 1998).

Uma dessas estratégias é a fuga à realidade, que pode ser conseguida com o uso de substâncias psicoativas. Para Huxley, Horowitz e Palmer (1983), o ser humano sempre buscou meios para "tirar férias da realidade" e de sua existência, geralmente enfadonha, desagradável ou dolorosa. De acordo com os autores, o homem primitivo explorou e recorreu em demasia e com bastante êxito aos caminhos farmacológicos para fugir do mundo, e neste sentido, o uso de drogas desempenhou um papel importante em quase todas as religiões primitivas e ainda desempenha atualmente em algumas.

Estudos têm demonstrado que o uso de drogas no local de trabalho produz efeitos negativos tanto para a saúde do indivíduo quanto para as empresas, por conta da baixa produtividade decorrente do alto absenteísmo e de dificuldades no desempenho das atividades 
(Azevedo, 2004). Dados da Organização Internacional do Trabalho (OIT) (2003) revelam que funcionários dependentes de drogas têm três vezes mais que os não dependentes a necessidade de tirar licenças médicas e cinco vezes mais, a probabilidade de sofrer ferimentos ou incapacitações resultantes de acidentes de trabalho.

De acordo com o relatório da OIT Problemas ligados ao álcool e drogas no local de trabalho: uma evolução para a prevenção (2003), determinadas condições de trabalho podem promover ou aumentar o uso de drogas. Estas condições seriam: riscos extremos de segurança; trabalho por turnos ou trabalho noturno; trabalho em locais remotos, com deslocamento para longe de casa; alterações nas tarefas ou velocidade de manuseamento do equipamento; conflitos de papéis; cargas de trabalho (excessivas e demasiada reduzida); desigualdade nas remunerações e demais benefícios; tensão psicológica (estresse) relacionada com o emprego; monotonia e ausência de criatividade; variedade ou controle; comunicações não satisfatórias; insegurança no emprego; e por fim, indefinição dos papéis.

Nos últimos anos foram realizadas análises reflexivas sobre o uso de álcool e outras drogas no local de trabalho (Beck \& David, 2007) com o emprego de diferentes métodos, como o qualitativo e 0 antropológico (Groisman \& Schneider, 2014), análises que aos poucos vêm sendo mais aprofundadas nos mais diversos cenários (Soares et al., 2007). Estudos de levantamento ou análises sobre as consequências do uso de drogas entre trabalhadores e suas relações de trabalho têm demonstrado a importância de se observar esse fenômeno, que está cada vez mais presente e enraizado em diversas áreas da vida e das instituições, por isso deve ser analisado com maior profundidade.

Estudos internacionais alertam para a problemática do uso de substâncias psicoativas associada ao stress constante no trabalho. Apontam o consumo entre categorias de trabalho, como: serviço de emergência (ambulância), trabalhadores rurais e enfermeiros (Jonson, Segesten, \& Mattsson, 2003; Díaz et al., 2011; Bletzer, 2014). Os autores demonstram que o consumo de substâncias psicoativas pode ser utilizado como uma válvula de escape para a dura rotina e o estresse no trabalho, situação que pode levar ao esfacelamento da vida social, laboral, assim como o surgimento de efeitos deletérios (cognitivos e orgânicos).

Deste modo, o presente artigo tem como objetivo fazer uma revisão de literatura sobre o uso de substâncias psicoativas e sua relação com o trabalho e o sofrimento, abordando, sobretudo, os mais diferentes tipos de substâncias e vários contextos de trabalho. 


\section{Método}

Foi realizada uma revisão da literatura nacional indexada nas bases de dados SciElo, Pepsic, Scopus e Web of Science, com os descritores em português: consumo de drogas e trabalho; dependência química e trabalho; drogas no trabalho; drogas, sofrimento e trabalho; e uso de drogas e sofrimento no trabalho. Como critério de inclusão procurouse localizar artigos científicos publicados no período entre 2005 e 2015 que fossem relacionados às pesquisas sobre o tema proposto: o uso de substâncias psicoativas por trabalhadores e/ou sua relação com o trabalho. A busca incluiu artigos originais e revisão de literatura PSI. Foram excluídas monografias, dissertações e teses e artigos que não relacionavam o uso de drogas ao trabalho.

$\mathrm{Na}$ busca realizada nas referidas bases de dados foi encontrado um número escasso de artigos que estivessem relacionados aos referidos temas. Ao todo, localizaram-se dezoito artigos indexados em revistas nacionais. Foram excluídos quatro artigos por não se encaixarem diretamente no tema proposto neste estudo, resultando em quatorze artigos, os quais são aqui analisados.

\section{Resultados e discussão}

\subsection{Apontamentos científicos da relação do uso de substâncias psicoativas e aspectos do trabalho}

Os estudos encontrados nas bases de dados demonstram que algumas categorias profissionais, se submetidas a determinadas condições de trabalho, poderiam favorecer a recorrência ao uso de certas substâncias psicoativas. A Tabela 1 apresenta as características dos estudos. 
Itamar José Felix J unior, Vanderléia de Lurdes Dal Castel Schlindwein, Paulo Renato Vitória Calheiros

Tabela 1. Relação dos estudos sobre uso de SPA's no trabalho identificados nas bases de dados SciElo, Pepsic, Scopus e Web of Science, no periodo de 2005 a 2015.

\begin{tabular}{|c|c|}
\hline Estudo & Delineamento \\
\hline Alves et al. (2005) & $\begin{array}{l}\text { Estudo de levantamento com } 198 \text { médicos em tratamento ambulatorial para } \\
\text { dependência química. }\end{array}$ \\
\hline $\begin{array}{l}\text { Castillo, Caufield, \& Gómez } \\
\text { Meza (2005) }\end{array}$ & $\begin{array}{l}\text { Estudo descritivo e correlacional com abordagem qualitativa com mulheres } \\
\text { na região metropolitana de Monterrey - México. }\end{array}$ \\
\hline David \& Caufield (2005) & $\begin{array}{l}\text { Estudo quantitativo e qualitativa para o mapeamento de fatores envolvidos } \\
\text { na relação entre uso de drogas lícitas e ilicitas e violência no trabalho, em } \\
\text { um grupo de mulheres das classes populares da cidade do Rio de Janeiro. }\end{array}$ \\
\hline Musayón \& Caufield (2005) & $\begin{array}{l}\text { Estudo quantitativo e qualitativo, que identifica fatores de risco } \\
\text { sóciodemográficos e de trabalho para o consumo de drogas em mulheres de } \\
\text { Zapallal, em Lima no Peru. Evidencia também a violência laboral. }\end{array}$ \\
\hline Martins \& Zeitoune (2007) & $\begin{array}{l}\text { Estudo descritivo de abordagem qualitativa com } 40 \text { sujeitos da área de } \\
\text { enfermagem de um hospital universitário. }\end{array}$ \\
\hline Soares et al. (2007) & $\begin{array}{l}\text { Estudo quantitativo, exploratório e descritivo com } 306 \text { trabalhadores de um } \\
\text { ambiente portuário. }\end{array}$ \\
\hline Beck \& David (2007) & $\begin{array}{l}\text { Estudo de análise reflexiva sobre o uso e abuso de substâncias psicoativas, } \\
\text { definido como farmacodependência, e o mundo do trabalho contemporâneo. }\end{array}$ \\
\hline Oliveira \& Furegato (2008) & Estudo qualitativo descritivo com 51 acadêmicos de enfermagem \\
\hline $\begin{array}{l}\text { Halpern, Ferreira, \& Silva } \\
\text { Filho (2008) }\end{array}$ & $\begin{array}{l}\text { Pesquisa bibliográfica dos registros e observações de grupoterapia de } \\
\text { militares com quadro de alcoolismo atendidos num Centro de Dep. Química } \\
\text { da Marinha. }\end{array}$ \\
\hline $\begin{array}{l}\text { Niel, Julião, Martin, \& } \\
\text { Silveira-Filho (2008) }\end{array}$ & Pesquisa qualitativa fenomenológica com 15 médicos anestesiologistas. \\
\hline Lima (2010) & $\begin{array}{l}\text { Ensaio que traz uma revisão de literatura reflexiva sobre o uso funcional e } \\
\text { disfuncional de drogas no contexto labora. }\end{array}$ \\
\hline Knauth et al. (2012) & $\begin{array}{l}\text { Levantamento com } 854 \text { motoristas de caminhão que visava avaliar os } \\
\text { fatores associados ao uso de estimulantes para se manterem acordados. }\end{array}$ \\
\hline Souza et al. (2013) & $\begin{array}{l}\text { Levantamento que se investiga o consumo de substâncias psicoativas entre } \\
\text { policiais civis e militares da cidade do Rio de Janeiro. }\end{array}$ \\
\hline Costa el al. (2015) & $\begin{array}{l}\text { Levantamento que objetivou identificar a prevalência do uso de drogas } \\
\text { psicoativas (anfetamina, metanfetamina, canabinoides, cocaina, opioides e } \\
\text { benzodiazepinicos) entre policiais militares do Estado de Goiás. }\end{array}$ \\
\hline
\end{tabular}

Em relação ao delineamento dos estudos, observou-se que seis deles $(43 \%)$, priorizaram abordagens qualitativas, outros quatro $(28,5 \%)$ empregaram métodos quantitativos e quatro (28,5\%), também apresentaram uma abordagem quantitativo-qualitativa. As pesquisas são oriundas do Brasil (doze), México (um) e Peru (um). O referencial teórico utilizado nos estudos foi: nove artigos apresentam uma abordagem multidisciplinar, com enfoque biopsicossocial, outros cinco 
se fundamentam nos pressupostos na Psicologia Social e Trabalho, buscando subsídios teóricos na abordagem fenomenológica e na Saúde Mental Relacionada ao Trabalho/SMRT para estabelecer a relação da saúde com a organização do trabalho.

Os estudos apontam que o tipo de substâncias psicoativas mais usadas entre as categorias profissionais foram: com $29 \%$ estão os profissionais da saúde (estudantes de enfermagem, enfermeiros e médicos) fazem uso de substâncias psicoativas (álcool, cigarros e ansiolíticos); $21 \%$ dos estudos foram entre os policiais militares e civis (álcool, tranquilizantes, anfetaminas, maconha e cocaína); em $21 \%$ das pesquisas de gênero, nas mulheres aparecem o consumo de drogas ilícitas, cigarros e álcool; e $14 \%$ são de estudos reflexivos que apontam para o uso abusivo de substâncias psicoativas no mundo do trabalho contemporâneo; $7 \%$ aparecem os profissionais de um ambiente portuário e caminhoneiros (álcool, rebites, maconha e outras drogas).

Os estudos encontrados que tratam da problemática do consumo de drogas entre trabalhadores enfatizam que esse fenômeno tem apresentado consequências adversas em diferentes classes trabalhadoras de ambos os gêneros e de diversas idades. Também alertam para o grau de adoecimento nas mais diversas categorias de trabalho, inclusive de quem ainda está se preparando para o mercado de trabalho.

Oliveira e Furegato (2008), em um estudo com acadêmicos de enfermagem, demonstraram que as drogas mais consumidas pelos acadêmicos eram o álcool (88\%), o cigarro (13\%) e ansiolíticos $(4 \%)$. Eles chegaram à conclusão de que os alunos de enfermagem, quando estão na fase de estágio, enfrentam uma carga horária estressante, o que por vezes os leva ao uso dessas substâncias.

Outro estudo de Martins e Zeitoune (2007) com enfermeiros de um hospital universitário destacam que, a sobrecarga de trabalho e também a facilidade de acesso às drogas está relacionada aos motivos para esse uso. Salientam que, o enfermeiro é um dos profissionais que está ligado diretamente com o público acometido por uso ou dependência de drogas.

Do mesmo modo, ao fazerem um levantamento com caminhoneiros do Rio Grande do Sul, Knauth et al. (2012) encontraram 12,4\% dos trabalhadores fazendo uso de "rebites" como estimulantes para se manterem acordados e que $70 \%$ relataram consumir álcool, dos quais $45,1 \%$ bebiam ao menos uma vez por semana. Os autores associam ao consumo elevado as às características da profissão, à pressão do tempo em que eles devem fazer as entregas e voltar para a estrada e à necessidade de manter-se em vigília para garantir a produtividade como motivos que levam à busca por substâncias estimulantes.

As características do trabalho pesado podem ser um dos motivos do uso de psicotrópicos entre trabalhadores de ambientes portuários. 
Soares et al. (2007) demonstram que entre trabalhadores portuários, $94,7 \%$ afirmaram já ter trabalhado com colegas alcoolizados e $77,27 \%$ afirmaram já ter trabalhado sob o efeito da maconha. Outro aspecto destacado é a motivação para o uso desses produtos: $40,15 \%$ deles os usavam por serem dependentes, e $8,33 \%$, para diminuir a fadiga. Nesse último caso os autores consideram o uso de tais substâncias como uma prática defensiva. Concluem que, o medo e o estigma fazem parte do cotidiano de quem usa drogas no trabalho, seja qual for sua classe ou categoria.

Ainda em relação ao uso de álcool e sua vinculação com trabalhadores, há reflexões sobre os casos de alcoolismo na carreira militar, especialmente na Marinha (Halpern, Ferreira, \& Silva Filho, 2008). Na Marinha brasileira foi implantado um centro que trata especialmente do assunto, o CEDEQ (Centro de Dependência Química), formado por uma equipe multidisciplinar que ouve e dá voz a quem é acometido pelo uso abusivo de álcool. Os autores salientam a partir dos atendimentos individuais e em grupos que, as pessoas têm medo de falar sobre o assunto, pois o alcoolismo é considerado ato vergonhoso, que pode chegar a uma vivência de decadência moral, seja pública ou privada (Gaulejac, 2006). Assim, é evidenciada uma cultura e tradição naval de uso de álcool, que se dá em parte pela fácil disponibilidade do álcool no seio daquela instituição. Outro ponto importante do estudo é que o medo de procurar ajuda se deve ao receio das penas, as quais produzem um achatamento progressivo da subjetividade que afeta a saúde psíquica e física, podendo levar a cometer erros (Halpern et al., 2008).

No mesmo sentido, o estudo de Alves et al. (2005) com médicos em tratamento por dependência química, demonstram que, as drogas mais consumidas foram o álcool, com $34,3 \%$, e outras drogas, com $28,3 \%$. Do total de usuários, $64 \%$ utilizavam duas ou mais drogas. 0 diagnóstico do uso e dependência da amostra, feito conforme os critérios do DSM-IV-TR, teve o álcool com mais prevalência $(72,7 \%)$, vindo a seguir a cocaína $(31,8 \%)$, os benzodiazepínicos $(28,2 \%)$, os opiáceos $(26,7 \%)$ e a maconha $(25,2 \%)$. Nesse estudo as especialidades mais frequentes foram anestesiologia e cirurgia. Assim como os outros estudos, este também aponta o silêncio dos profissionais sobre o tema e o medo de procurar ajuda e expõe algumas considerações relevantes, como a alta automedicação, e sugere que serviços de orientação sejam oferecidos aos profissionais na formação e durante a vida profissional. Niel, Julião, Martin e Silveira Filho (2008) Niel et al. (2008) afirmam que, um dos motivos para o uso de substâncias por anestesiologistas pode ser a facilidade de acesso às drogas e consideram isso como um dos "gatilhos" para o consumo.

Essa não é uma realidade ou um problema só do Brasil. Dois estudos com mulheres, um em Lima, capital do Peru, e outro em Monterrey, 
no México, investigaram esse fenômeno relacionando-o com a violência laboral (Musayón \& Caufield, 2005; Castillo, Caufield, \& Gomez Meza, 2005). O uso de álcool foi o mais citado, com 52,8\% das participantes em Lima e 37,1\% em Monterrey. Acerca da violência, o estudo de Musayón e Caufield (2005) comprova que existe uma associação entre violência verbal e consumo de drogas ilícitas: aquelas que sofreram esse tipo de agressão sofrem 7,80 vezes mais o risco de consumir alguma droga ilícita, se comparadas com aquelas que não foram vítimas.

Por sua vez, Castillo, Caufield e Gomez Meza (2005) encontraram uma associação positiva entre o índice de violência e o consumo de drogas $(p<0,05)$. Essas duas pesquisas demonstram a importância de analisar as novas facetas do consumo de drogas por mulheres, principalmente de álcool, pois este consumo tem aumentado nos últimos anos em situações como as de trabalho, de violência e de discriminação de gênero.

David e Caufield (2005) foram no mesmo sentido de Castillo et al. (2005) e Musayón e Caufield (2005), porém com mulheres da periferia da cidade do Rio de Janeiro. Esse estudo teve resultados parecidos, tendo o álcool como a droga mais consumida e a violência verbal como a causa predominante do seu consumo no ambiente de trabalho; além disso, 33\% das mulheres trabalhadoras afirmaram ter sofrido algum tipo de violência psicológica, que inclui humilhações, deboche, ser "bode expiatório", gritar, etc. Também foi evidenciado o uso de fármacos como ansiolíticos e barbitúricos, por isso deve-se dar e maior atenção a esse fenômeno cada vez mais presente entre as trabalhadoras, as quais podem estar se automedicando ou sendo medicadas sem real necessidade.

Souza, Schenker, Constantino e Correia (2013) analisaram, na cidade do Rio de Janeiro, o consumo de drogas entre policiais civis e militares, os quais exercem uma das mais perigosas profissões, pois o risco de morte é iminente e muitas vezes o trabalho é precarizado ou sucateado. As substâncias de consumo mais frequente entre os policiais civis e militares foram o tabaco $(23,3 \%$ e $19,1 \%$, respectivamente), o álcool (respectivamente, $12 \%$ e $11 \%$ ) e os tranquilizantes $(13,3 \%$ e $10,1 \%$, respectivamente). O uso diário de álcool chamou a atenção pelos índices de consumidores: $12 \%$ e $10,9 \%$ entre civis e militares, respectivamente.

No mesmo sentido, Costa et al. (2015) encontraram dados a partir da coleta voluntária de urina de policiais militares do Estado de Goiás. Esses dados demonstraram que $97,66 \%$ dos resultados foram negativos em relação ao uso de substâncias, mas entre os casos positivos a distribuição se deu entre os benzodiazepínicos $(57,1 \%)$, os canabinoides $(28,6 \%)$ e as anfetaminas (14,3\%). O uso acentuado dessas substâncias pelos policiais pode estar relacionado aos estresses psicológicos e emocionais vividos e relatados por eles no 
desempenho de suas funções - relação que já foi descrita em estudos internacionais (Souza et al., 2013), causando preocupação pelo fato de as polícias se configurarem como uma das classes com maior frequência de suicídios.

Por fim, Lima (2010) traz uma análise reflexiva e coerente sobre o uso funcional e disfuncional de drogas no contexto laboral, com as teorias que vêm estudando os processos intersubjetivos do trabalho, como a da Psicodinâmica do trabalho, que classifica o uso de drogas no trabalho como funcional e disfuncional, afirmando que a primeira classe (a funcional) seria uma "ferramenta" de trabalho que ajuda o trabalhador a produzir mais e aguentar a fadiga, a carga horária e a pressão, além das questões subjetivas subjacentes. $O$ uso disfuncional se daria após o uso abusivo funcional, acarretando assim problemas maiores para o usuário e para outros. O indivíduo já não usa para superar as dificuldades, o uso passa a ser um fim em si mesmo (Lima, 2010).

\subsection{Evidências teóricas da relação entre o uso de substâncias psicoativas, a intensificação do sofrimento no trabalho e os transtornos mentais e comportamentais.}

Nos últimos anos verifica-se a intensificação de novas morfologias laborais, entre elas a precarização do trabalho (Antunes, 2009) - fato que tem contribuído para o sofrimento relacionado à atividade laboral (Dejours, 2007). Afirma Seligmann-Silva (2011, p. 35) que “(...) o trabalho, conforme a situação, tanto poderá fortalecer a saúde mental quanto torna-la vulnerável, e mesmo gerar distúrbios que se expressarão coletivamente e no plano individual".

Análises que usam o campo de abordagem da Saúde Mental Relacionada ao Trabalho (SMRT) (Sato, 2003; Le Guillant, 2006; Silva-Seligmann, 2011; Dejours, 2012 e outros) têm focalizado os diversos fatores de adoecimento que possuem relação com a atividade laboral. Atualmente a dependência química vem sendo considerada uma doença passível de tratamento - o que é bem diferente dos tempos em que era tida como um desvio de caráter, sendo coerente com o modelo biopsicossocial de saúde em voga na atualidade (Pratta \& Santos, 2009). A OMS (2001) tem tratado a dependência química em sua complexidade como uma problemática crônica e social. Da mesma forma ela tem sido encarada também pelos teóricos que estudam o trabalho em suas mais diversas facetas - como Christophe Dejours, com a abordagem da "Psicodinâmica do Trabalho", que trata sobre os efeitos negativos do trabalho e a influência dessa condição no processo de adoecimento e sofrimento do indivíduo.

Sobre isso, Dejours (1992) esclarece que, o alcoolismo pode não estar ligado diretamente ao sofrimento gerado pelo trabalho, pois 
parte desse comportamento seria proveniente de estruturas da personalidade do próprio indivíduo. No entanto, a busca pelo álcool também pode ser utilizada como estratégia de defesa coletiva frente ao sofrimento no trabalho, já que o álcool tem uma característica gregária e de socialização.

Um estudo de Lima (2004) realizado em 3.912 prontuários de pacientes que passaram em seis clínicas psiquiátricas, incluindo o hospital psiquiátrico do Manicômio Judiciário de Minas Gerais, revelou que os policiais militares apresentaram maior frequência de alcoolismo $(54,5 \%)$ em relação a outras categorias profissionais e que algumas categorias profissionais tendem a apresentar distúrbios mentais bastante específicos. Os distúrbios mentais relacionados ao uso de álcool foram detectados em 639 pacientes, sendo que a análise probabilística revelou que algumas categorias profissionais como transportes/motorista, polícia militar/policiais, trabalhadores da construção civil e mecânico - sofrem maiores riscos de apresentar transtornos mentais pelo uso de álcool do que outras categorias. Ademais, este estudo evidencia que certas categorias profissionais podem intensificar as vivências de sofrimento no trabalho. Vários estudos apontam que 0 adoecimento tem nexo causal com 0 trabalho, pois estudos de vários autores apontam existir relação entre - adoecimento e certas formas de organização e determinadas condições de trabalho (Sivadon 1993; Sato et al., 1993; Le Guillant et al., 1994; Le Guillant, 2006; Merlo, Jacques, \& Hoefel, 2001; Lima, Assunção, \& Francisco, 2002; Lima, 2004, 2006; Schlindwein, 2013; Schlindwein \& Morais, 2014; Mattos \& Schlindwein, 2015).

Os autores citados, embora adotem, defendem em comum a tese de que $o$ adoecimento mental tem relação com certas formas de organização do trabalho, reafirmando que certas categorias profissionais desenvolvem quadros clínicos bastante específicos e reveladores das condições de trabalho às quais são submetidas. Sendo assim, a questão não é ater-se exclusivamente ao caráter patogênico do trabalho, sendo necessário também relacioná-lo à história de vida do sujeito, com seu modo de julgar e de conduzir sua vida, seu sistema de valores e a representação de mundo forjada por essa história.

Le Guillant, pioneiro da Psicopatologia do Trabalho, propõe uma clínica baseada na compreensão das condições de vida e de trabalho dos pacientes, conjugada com o resgate de sua história de vida. Nos seus estudos, em 1950, com as telefonistas, mecanógrafos de Paris concluiu que, a forma de organização do trabalho nessas atividades é a causa do adoecimento denominado "síndrome geral da fadiga nervosa". Segundo o autor, na atividade das telefonistas e mecanógrafos observa-se que: "as operadoras sofrem por trabalharem como "robôs", por executarem um trabalho "mecânico", por estarem impedidas de tomar iniciativas ou de organizar elas 
mesmas o seu trabalho, além de não trazerem nenhuma contribuição pessoal para sua atividade" (Lima, 2006, p. 185).

Estudos em Psicodinâmica do Trabalho desenvolvidos por Mattos \& Schlindwein (2015), numa instituição pública de Rondônia, apontam os efeitos desestabilizadores da saúde mental no trabalho de servidores públicos federais após a implantação de uma nova ferramenta de gestão, chamada de Balanced Scorecard (BSC), com métodos baseados na avaliação sistemática das atividades, com foco na excelência e efetividade dos procedimentos. Os trabalhadores associam os mecanismos de controle, pressões e rigidez utilizados no trabalho como principais responsáveis pelos sintomas que motivaram os afastamentos no trabalho por transtornos mentais e comportamentais nos últimos anos.

Todos os autores corroboram que a história pessoal não pode ser desconsiderada na análise do caráter patogênico do trabalho, pois ambos - a saúde mental e o trabalho- se integram a um contexto psicológico: a primeira é o signo das representações de mundo que caracteriza o jeito de ser do indivíduo, o jeito de julgar e conduzir sua vida. Esta história fará parte do processo de adoecimento no trabalho, do caráter patogênico do trabalho.

De qualquer forma, concorda-se com Le Guillant (2006, p. 348) quando escreve que, em seu entendimento, a plena apreensão do caráter patogênico do trabalho só será possível quando for estabelecida a relação das condições dessa atividade com toda a história de vida do paciente, com suas maneiras de julgar e comportar-se e com suas representações do mundo forjadas por esta história.

\section{Considerações finais}

O presente artigo teve como objetivo analisar a literatura PSI brasileira de estudos que enfocassem o consumo de substâncias psicoativas por trabalhadores. Todos os estudos aqui referidos demonstram que essa problemática não é nova, mas mesmo assim as empresas e instituições, de certa maneira, não têm dado a esse fenômeno a devida importância. Um dos problemas sociais relacionados à utilização de substâncias psicoativas é o desemprego. Muitas empresas demitem o funcionário quando descobrem que ele usa essas substâncias e isso configura o medo, muito presente nos estudos mencionados nas mais diversas categorias. O consumo de drogas se tornou um problema de saúde pública que interfere em outros setores da sociedade, contribui para a redução da produtividade e aumenta a probabilidade de acidentes de trabalho, trazendo riscos para a vida tanto do indivíduo quanto de outras pessoas. 
O uso de drogas pode acarretar novos problemas no trabalho, que vão desde punições, transferências compulsórias, rebaixamento de função, imposição de tarefas menos interessantes ou o isolamento puro e simples do trabalhador, com a demissão (Lima, 2010). Encaminhá-lo para o tratamento é outro problema, pois nem sempre ocorre, e pode acontecer que o empregado se veja como culpado e assim se torne o único responsável pela sua recuperação. É preciso dizer que o trabalho em si não é o maior motivador para consumo de substâncias, mas quando as condições de trabalho são desgastantes, estressantes e desmotivadoras para o trabalhador, aumentam as chances de seu refúgio no uso de alguma droga, seja esta lícita ou ilícita. Conforme se verificou nesta pesquisa, a violência no trabalho também é um fator relacionado ao uso de drogas que merece mais investigações em futuras pesquisas, uma vez que o ambiente de trabalho tem se configurado como um lugar onde as diferenças existem e não são respeitadas, e como consequência, a violência psicológica tem predominado em diversas atividades profissionais.

Ainda assim, vários estudos citam que a estigmatização pelo medo de possíveis punições é uma das possíveis questões a serem consideradas, a fim de se trabalhar com esta população, principalmente no tocante ao uso de substâncias psicoativas para aumentar a produtividade no contexto laboral. Os estudos indicam que seus resultados podem não representar fidedignamente a verdade, pois nem sempre a realidade foi passada para os pesquisadores. O relato sobre o uso de drogas pelo trabalhador, sua primeira vez e os motivos pelos quais ainda usa, é importante para esclarecê-lo e ajudá-lo a se tratar. A procura tardia pelo tratamento, principalmente quando o trabalhador tem medo de perder o emprego ou sente dificuldade em ter acesso ao tratamento adequado, leva à cronificação do problema (Todrá, Daldon, Santos, \& Lancman, 2010). A maioria dos estudos aqui analisados trazem dados quantitativos, 0 que é importante para se ter uma dimensão do problema. Outros trazem dados quantitativos e também qualitativos, o que proporciona uma análise mais profunda do tema. As pesquisas qualitativas em relação às drogas e ao trabalho são primordiais para um maior entendimento dessa problemática. Na área da saúde, principalmente nos últimos anos, tem-se dado destaque aos estudos qualitativos, passando-se à interlocução aberta com os participantes da pesquisa para torná-la mais produtiva no tocante à singularidade das experiências investigadas e à pluralidade de situações e condicionamentos que influenciam estas experiências (Groisman \& Schneider, 2014).

Dejours (2004), ao afirmar que o trabalho preenche a lacuna entre o prescrito e o real, concorda que o sofrimento está interligado com a subjetividade, a qual, por sua vez, está relacionada ao real. A organização do trabalho é um fator determinante para o sofrimento, 
portanto tem relação com o sofrimento dos trabalhadores e com a consequente utilização de álcool, drogas e outras substâncias. No Brasil tem-se notado nos últimos anos um aumento de casas de recuperação de pessoas com problemas de uso de álcool e outras drogas, e como já se sabe, essas novas instituições de tratamento nem sempre oferecem um tratamento sistematizado, como bem o indica a literatura cientifica. A rede assistencial para tratamento ainda é deficiente e muitas vezes não leva em conta os processos que influenciam o consumo de drogas ou substâncias psicoativas no trabalho, quando se sabe que o próprio trabalho é primordial para o processo de recuperação. Por isso novas pesquisas devem ir nesse sentido, para que as discussões sobre esse tema façam parte dos processos de prevenção, intervenção e pós-tratamento para que o trabalhador volte a inserir-se no mercado de trabalho.

Por fim, considera-se que os estudos aqui apresentados sobre a problemática do uso de álcool e substâncias psicoativas relacionados ao trabalho apontam vários fatores associados, como agravantes socioeconômicos, violência psicológica, intensificação, precarização e condições de trabalho, ainda a OIT (2003) aponta fatores socioculturais e religiosos.

\section{Referências}

Alves, H. N. P., Surjan, J. C., Nogueira-Martins, L. A., Marques, A. C. P. R., Ramos, S. P., \& Laranjeira, R. (2005). Perfil clínico e demográfico de médicos com dependência química. Revista da Associação Médica Brasileira, 51(3), 139-43.

Antunes, R. (2009). O trabalho, sua nova morfologia e a era da precarização estrutural. Theomai: estudios sobre sociedad, naturaleza y desarrollo, 5(19), 47-57.

Azevedo, R. C. S. (2004). Drogas e Trabalho. In: Guimarães, L. A. M., \& Grubits, S. (Orgs.) Série saúde mental e trabalho (pp. 3549), Vol. 1, num 35. São Paulo: Casa do Psicólogo.

Barreto, M., \& Heloani, R. (2014). O assédio moral como instrumento de gerenciamento. In: Merlo, Á. R. C., Bottega, C. G., \& Perez, K. V. (Orgs.). Atenção à saúde mental do trabalhador: sofrimento e transtornos psíquicos relacionados ao trabalho (pp. 52-74). Porto Alegre: Editora Evangraf.

Beck, L. M., \& David, H. M. S. L. (2007). O abuso de drogas e o mundo do trabalho: possibilidades de atuação para o enfermeiro. Escola Anna Nery Revista de Enfermagem, 11(4), 706-711.

Bletzer, K. V. (2014). New Drug Use Among Agricultural Workers. Substance use \& misuse, 49(8), 956-967. 
Brant, L. C., \& Minayo-Gomez, C. (2004). A transformação do sofrimento em adoecimento: do nascimento da clínica à psicodinâmica do trabalho. Ciência e saúde coletiva, 9(1), 213223.

Castillo, M. M. A., Caufield, C., \& Gómez Meza, M. V. (2005). Consumo de drogas y violencia laboral en mujeres trabajadoras de Monterrey, NL, México. Revista. Latinoamericana de Enfermagem, 13(spe2), 1164-1168.

Codo, W. (2002). A arte de não fazer. O funcionário público faz o que precisa ser feito? In W. Codo, \& M. G. Jacques (Orgs.) Saúde mental e trabalho: leituras (pp.296-308). Petrópolis, RJ : Vozes.

Codo, W. (2004). O trabalho enlouquece? Um encontro entre a clínica e o trabalho. Petrópolis, RJ: Vozes.

Costa, S. H., Yonamine, M., Martins Ramos, A. L., Ferreira Oliveira, F. G., Rodrigues, C. R., \& da Cunha, L. C. (2015). Prevalência do uso de drogas psicotrópicas em unidades da polícia militar. Revista Ciência \& Saúde Coletiva, 20(6), 1843-1849.

David, H. M. S. L., \& Caufield, C. (2005). Mudando o foco: um estudo exploratório sobre uso de drogas e violência no trabalho entre mulheres das classes populares da cidade do Rio de Janeiro, Brasil. Rev. Latino Americana de Enfermagem, 13(spe), 11481154.

Dejours, C. (1992). A loucura do trabalho: estudo de psicopatologia do trabalho. São Paulo, SP: Cortez.

Dejours, C. (2004). Subjetividade, trabalho e ação. Revista Produção, 14(3), 27-34.

Dejours, C. (2007). A banalização da injustiça social. Rio de Janeiro: Editora FGV.

Dejours, C. (2010). Trabalho e saúde mental: da pesquisa à ação. In: Dejours, C., Abdouchele, E. \& Jayet, C (Orgs.). Psicodinâmica do Trabalho: Contribuições da Escola Dejouriana à Análise da Relação Prazer, Sofrimento e Trabalho (pp. 45-65). São Paulo, SP: Atlas.

Dejours, C. (2011). Da psicopatologia à psicodinâmica do trabalho. In: Lancman, S., Sznelwar, L. I. Da psicopatologia à psicodinâmica do trabalho (pp. 57-123). Rio de Janeiro: Fiocruz.

Dejours, C. (2012). Psicodinâmica do Trabalho: contribuições da escola dejouriana à análise da relação prazer, sofrimento e trabalho. São Paulo: Atlas.

Díaz, L., Ulloa, C. M., Taubert De Freitas, F., Amorim, L., Barcelos, M. C., Valenzuela, S. V., \& Do Carmo Cruz, R. (2011). El uso de drogas en el personal de enfermería. Ciencia y enfermería, $17(2), 37-45$. 
Enriquez, E. (2014). O trabalho, essência do homem? O que é o trabalho?. Cadernos de Psicologia Social do Trabalho, 17 (spe), 163-176.

Gaulejac, V. de (2006). As origens da vergonha. São Paulo: Via Lettera.

Groisman, A., \& Schneider, J. (2014). Pesquisa qualitativa, saúde e uso de drogas: desdobramentos e implicações teóricas, analíticas e epistemológicas da utilização da técnica da entrevista de fala aberta. Revista Portuguesa de Saúde Pública, 32(1), 37-44.

Halpern, E. E., Ferreira, S. M. B., \& Silva Filho, J. F. D. (2008). Os efeitos das situações de trabalho na construção do alcoolismo de pacientes militares da Marinha do Brasil. Cadernos de Psicologia Social do Trabalho, 11(2), 273-286.

Huxley, A., Horowitz, M., \& Palmer, C. (1983). Moksha: textos sobre psicodélicos e a experiência visionária, 1931-1963. Rio de Janeiro, RJ : Editora Globo.

Jardim, S. (2011). Depressão e trabalho: ruptura de laço social. Revista Brasileira de Saúde Ocupacional, 36 (123), 84-92.

Jonsson, A., Segesten, K., \& Mattsson, B. (2003). Post-traumatic stress among Swedish ambulance personnel. Emergency medicine journal, 20(1), 79-84.

Knauth, D. R., Pilecco, F. B., Leal, A. F., Seffner, F., \& Teixeira, A. M. F. (2012). Manter-se acordado: a vulnerabilidade dos caminhoneiros no Rio Grande do Sul. Revista de Saúde Pública, 46(5), 886-893.

Laranjeira, R. R. (2005). Perfil clínico e demográfico de médicos com dependência química. Revista da Associação Médica Brasileira, 51(3), 139-43.

Le Guillant, L. (2006). O trabalho e a fadiga. In M.E.A. Lima, M. E. A. L. (Org.), Escritos de Louis Le Guillant: da ergoterapia à psicopatologia do trabalho (pp. 218-241). Petrópolis: Vozes.

Le Guillant, L., Roelens, R., Begoin, J., Béquart, P., Hansen, M., \& Lebreton, F. (1984). A neurose das telefonistas. Revista Brasileira de Saúde Ocupacional, 12(47), 7-11.

Lima, M. E. A. (1998). A Psicopatologia do trabalho. Psicologia: Ciência e Profissão, 18(2), 10-15.

Lima, M. E. A., Assunção, A. A., Francisco, D. S. M. J. Lima, M. E. A., Assunção, A. A., \& Francisco, D. S. M. J. (2002). Aprisionado pelos ponteiros de um relógio: o caso de um transtorno mental desencadeado no trabalho. In M.D.G. Jacques, W. Codo. (Org.) Saúde Mental \& Trabalho: Leituras (pp. 209-246). Petrópolis: Vozes.

Lima, M. E. A. (2004). A relação entre distúrbio mental e trabalho: evidências epidemiológicas recentes. In W. Codo (Org.), O trabalho enlouquece? (pp. 139-160). Petrópolis, RJ : Vozes. 
Lima, M. E. A. (Org.). (2006). Escritos de Louis Le Guillant: da ergoterapia à psicopatologia do trabalho. Petrópolis: Vozes.

Lima, M. E. A. (2010). Dependência química e trabalho: uso funcional e disfuncional de drogas nos contextos laborais. Revista Brasileira de Saúde Ocupacional, 35(122), 260-268.

Ludermir, A. B. (2005). Associação dos transtornos mentais comuns com a informalidade das relações de trabalho. Jornal Brasileiro de Psiquiatria, 54(3), 198-204.

Martins, E. R. C., \& Zeitoune, R. C. G. (2007). As condições de trabalho como fator desencadeador do uso de substâncias psicoativas pelos trabalhadores de enfermagem. Escola Anna Nery Revista de Enfermagem, 11(4), 639-44.

Mattos, C. B. M., \& Schlindwein, V. L. Dal C. (2015). Excelência e produtividade: novos imperativos de gestão no serviço público. Revista Psicologia \& Sociedade, 27(2), 322-331.

Merlo, Á. C., Jacques, M. G. C, \& Hoefel, M. G. (2001). Trabalho de Grupo com Portadores de Ler/Dort: Relato de Experiência. Psicologia: Reflexão e Crítica, 14(1), 253-258. Recuperado em 02 de Fevereiro, 2012, de http: //www.scielo.br/scielo.php?script=sci_arttext\&pid=S0102$79722001000100021 \&$ lng =pt\&nrm=iso\&tlng $=$ pt

Musayón, Y., \& Caufield, C. (2005). Consumo de drogas e violência no trabalho feminino Zapallal - Lima/Perú. Revista LatinoAmericana de Enfermagem, 13(spe2), 1185-1193.

Niel, M., Julião, A. M., Martin, D., \& da Silveira Filho, D. X. (2008). Uso de drogas entre anestesiologistas no contexto das relações de trabalho. Revista Brasileira em Promoção da Saúde, 21(3), 194-200.

Oliveira, E. B., \& Furegato, A. R. F. (2008). O trabalho do acadêmico de enfermagem como fator de risco para o consumo de álcool e outras drogas. Revista Latino-Americana de Enfermagem, 16 (spe), 565-571.

Organização Internacional do Trabalho, OIT (2003). Problemas ligados ao Álcool e a Drogas no local de Trabalho: Uma evolução para a prevenção.

Organização Mundial da Saúde (2001). Transtornos devido ao uso de substâncias. In: Organização Pan-Americana da Saúde \& Organização Mundial da Saúde (Org.). Relatório sobre a saúde no mundo. Saúde Mental: nova concepção, nova esperança (pp. 58-61). Brasília: Gráfica Brasil.

Pratta, E. M. M., \& Santos, M. A. D. (2009). O processo saúde-doença e a dependência química: interfaces e evolução. Psicologia: Teoria e Pesquisa, 25(2), 203-211.

Rosa, C. D., \& Carlotto, M. S. (2005). Síndrome de Burnout e satisfação no trabalho em profissionais de uma instituição hospitalar. Revista da SBPH, 8(2), 1-15. 
Sato, L., Araújo, M. D, Udihara, M. L., Settimi, M. M., \& Silvestre, M. $P$ (1993). Atividade em grupo com portadores de LER e achados sobre a dimensão psicossocial. Revista Brasileira de Saúde Ocupacional, 21(79), 49-62.

Sato, L. (2003) Subjetividade, saúde mental e LER. In: Ruiz, R. C. et al. Um mundo sem LER é possível (pp. 62-78). Montevidéu, Uruguai: Del-Sur.

Seligmann-Silva, E. (2011). Trabalho e desgaste mental: o direito de ser dono de si mesmo. São Paulo: Cortez.

Schlindwein, V. L. Dal C. (2013). Histórias de vida marcadas por humilhação, assédio moral e adoecimento no trabalho. Psicologia \& Sociedade, 25(2), 430-439. Recuperado em 05 de junho, 2015, de http: //www.scielo.br/scielo.php?script=sci_arttext\&pid=S0102$71822013000200020 \&$ Ing =en\&tlng =pt

Schlindwein, V. L. Dal C., \& Morais, P. R. (2014). Prevalência de transtornos mentais e comportamentais nas instituições públicas federais de Rondônia. Cadernos de Psicologia Social do Trabalho (USP), 17(1), p.117-127.

Sivadon, P. (1993). Psychiatrie et socialités. Paris: Érès.

Soares, J. F. D. S., Cezar-Vaz, M. R., Cardoso, L. D. S., Soares, M. C., Costa, V. Z. D., \& Almeida, C. V. (2007). O risco do uso de drogas no trabalho portuário: estudo no extremo sul do Brasil. Escola Anna Nery Revista de Enfermagem, 11(4), 593-8.

Souza, E. R., Schenker, M., Constantino, P., \& Correia, B. S. C. (2013). Consumo de substâncias lícitas e ilícitas por policiais da cidade do Rio de Janeiro. Revista Ciência \& Saúde Coletiva, 18(3), 667-676.

Todrá, R. C., Daldon, M. T. B., dos Santos, M. D. C., \& Lancman, S. (2010). Facilitadores e barreiras para o retorno ao trabalho: a experiência de trabalhadores atendidos em um Centro de Referência em Saúde do Trabalhador-SP, Brasil. RBSO, 35(121), 10-22.

Violanti, J. M., Marshall, J. R., \& Howe, B. (1985). Stress, coping, and alcohol use: The police connection. Journal of Police Science \& Administration, 13(2), 106-110.

\section{Endereço para correspondência}

I tamar J osé Felix J unior

Universidade Federal de Rondônia

Programa de Pós-graduação em Psicologia

Centro Regional de Referência em Álcool e outras drogas de Rondônia

Campus - BR 364, Km 9,5, CEP 76801-059, Porto Velho - RO, Brasil

Endereço eletrônico: itamar.junior44@hotmail.com

Vanderléia de Lurdes Dal Castel Schlindwein

Universidade Federal de Rondônia

Programa de Pós-graduação em Psicologia 
Campus - BR 364, Km 9,5, CEP 76801-059, Porto Velho - RO, Brasil

Endereço eletrônico: vdalcastel@gmail.com

\section{Paulo Renato Vitória Calheiros}

Universidade Federal de Rondônia

Departamento de Psicologia

Centro Regional de Referência em Álcool e outras drogas de Rondônia

Campus - BR 364, Km 9,5, CEP 76801-059, Porto Velho - RO, Brasil

Endereço eletrônico: paulocalheiros@unir.br

Recebido em: 22/09/2015

Reformulado em: 14/10/2015

Aceito para publicação em: 24/10/2015

\section{Notas}

* Psicólogo. Mestrando pelo Programa de Pós-graduação Mestrado Acadêmico em Psicologia da Universidade Federal de Rondônia (UNIR).

** Professora Doutora. Docente do curso de Psicologia da Universidade Federal de Rondônia, Porto Velho, Brasil e coordenadora do Programa de Pós-Graduação em Psicologia/MAPSI da UNIR.

*** Professor Doutor. Docente do Departamento de Psicologia da UNIR. Docente do Programa de Pós-graduação Mestrado Acadêmico em Psicologia da UNIR. Coordenador do Centro Regional de Referência em Crack, álcool e outras drogas. 